\title{
DESENVOLVIMENTO DE ERP:
}

\section{ESTUDO SOBRE A INSERÇÃO DE}

MECANISMOS DE CONTROLE

DE HEURÍSTICAS

ERP DEVELOPMENT: STUDY ON THE INSERTION OF HEURISTIC CONTROL MECHANISMS

Ana Carolina Reis Covelli

Mestre em Controladoria e Finanças Empresariais pela Universidade Presbiteriana Mackenzie (UPM).

Coordenadora de Serviços de TI na Totvs.

E-mail:carolcovelli@hotmail.com

\section{Ana Maria Roux Valentini Coelho Cesar}

Professora do Programa de Pós-Graduação em Controladoria e Finanças Empresariais da UPM.

E-mail:anamaria.cesar@mackenzie.br 


\section{RESUMO}

A proposta dos sistemas integrados de gestão é transformar, com agilidade e eficiência, dados operacionais em informações válidas ao processo de decisão. Analisaram-se neste estudo a participação dos sistemas integrados de gestão no processo decisório e a eventual influência de fatores cognitivos nesse processo. Com abordagem qualitativa, foram feitas entrevistas com profissionais que ocupam cargos estratégicos para a tomada de decisão em empresas situadas na cidade de São Paulo e que utilizam sistema integrado de gestão Totvs. Os resultados obtidos apontam que decisões financeiras são fortemente apoiadas em informações objetivas obtidas pelos sistemas. As decisões relacionadas à operação são apoiadas em sistemas no que se refere a medidas estruturadas e programadas, porém sofrem influência de vieses cognitivos por estarem fortemente relacionadas às pessoas; já as decisões estratégicas, mesmo apoiadas nos relatórios dos sistemas integrados, demonstram forte presença de vieses cognitivos relacionados à experiência profissional do gestor. Ou seja, a empresa precisa considerar a possibilidade de criar caminhos em formato de heurísticas (como regras default) para minimizar eventuais erros de interpretação ou de ajustes insuficientes realizados pelos gestores.

\section{PALAVRAS-CHAVE}

Ferramentas de gestão. Modelo cognitivo. Sistema de informação. Tomada de decisão.

\section{ABSTRACT}

The proposal of the integrated management systems is to transform, with agility and efficiency, operational data into valid information for the decision-making process. In this study, the participation of integrated management systems in the decision-making process and the possible influence of cognitive factors in this process were analyzed. With a qualitative approach, interviews were carried out with professionals who occupy strategic positions for decision making in companies located in the city of São Paulo and that use Totvs integrated management system. The results obtained show that financial decisions are strongly supported by the objective information obtained by the systems. The decisions related to the operation are supported by systems regarding structured and programmed measures, however, they are influenced by cognitive biases because they are strongly related to people; while strategic decisions, even supported by integrated systems reports, show a strong presence of cognitive biases related to the manager's professional experience. In other words, the company needs to consider the possibility 
of creating paths in the form of heuristics (such as default rules) to minimize any errors of interpretation or insufficient adjustments made by managers.

\section{KEYWORDS}

Management tools. Cognitive model. Information system. Decision making. 


\section{INTRODUÇÃO}

No contexto empresarial, a informação é um recurso estratégico, portanto, deve ser monitorada, integrada e preservada. A informação agrega valor às operações à medida que é estrategicamente utilizada; além disso, é necessário observar a segurança de sua fonte (Amaral \& Sousa, 2011). Todavia, apesar da grande quantidade de informações a que os indivíduos são expostos a cada instante, o ser humano tem limitações em sua capacidade de absorção dessas. Por meio de sua pesquisa Pennings, Garcia e Hendrix (2005) destacam o modelo linear de tomada de decisão e as contribuições trazidas pela Neurociência, que apresentam mecanismos cognitivos que reduzem o fluxo das informações recebidas pelos indivíduos, tornando possível absorvê-las.

Em um cenário economicamente rumoroso, estar munido de informações fidedignas e tempestivas torna o processo decisório mais ágil e assertivo, viabilizando melhores resultados por meio da gestão estratégica dos recursos (Januzzi, Falsarella \& Sugahara, 2014). A informação torna-se relevante à medida que, ao ser adquirida e bem interpretada, tem a capacidade de proporcionar poder ao indivíduo que a detém. O processo decisório das organizações pautado em informações tem sua relevância relacionada à forma como as informações são ofertadas, processadas e compreendidas pelo gestor, de modo a serem aplicadas ao processo decisório.

A tecnologia da informação desenvolveu-se com o intuito de otimizar o processo de geração, monitoramento e segurança das informações. Além disso, havia a necessidade de se estabelecer estratégias e instrumentos para consolidar e disponibilizar informações por meio de recursos tecnológicos aos gestores de organizações.

Fundamentados pela teoria da informação, os sistemas integrados de gestão, ou também chamados enterprise resources plannings (ERP), baseiam-se na estrutura organizacional das empresas e são utilizados como ferramenta para coletar, registrar e classificar informações a serem disponibilizadas aos usuários, no momento necessário, para que sejam utilizadas no processo decisório. Esses sistemas foram desenvolvidos com a finalidade de conduzir informações aos gestores organizacionais de modo a facilitar, agilizar e otimizar o processo decisório. São importantes ferramentas de apoio ao executivo, pois 
oferecem a possibilidade de balizar as decisões não estruturadas, ou seja, aquelas que ainda não têm semelhança direta com outros problemas enfrentados pela organização. A ferramenta também é aplicada no processo de tomada de decisões programadas, ou seja, para solucionar problemas já conhecidos pela organização.

Os ERPs, enquanto condutores de dados no formato de informação, são sistemas que integram as áreas operacionais da organização em que atuam os subsistemas, também chamados de módulos, por meio de pontos de semelhança entre eles. Esses dados são transformados de forma mecânica, ou seja, processados por tabelas e programas de modo a serem estruturados, posteriormente organizados e armazenados, possibilitando a oferta de informações em tempo real. Paralelamente, existe nas organizações a necessidade de administrar e tomar decisões operacionais com a finalidade de manter a companhia financeiramente rentável e economicamente saudável.

A decisão é considerada um amplo processo embasado por questões lógicas e psicológicas que se aplicam não somente a fatos concretos, mas, principalmente, à maneira como esses fatos são percebidos. Ela exige raciocínio, discernimento e responsabilidade. Os ERPs colaboram para a tomada de decisão à medida que oferecem ao gestor dados acerca da operação empresarial de forma estruturada e objetiva. Tais dados, quando organizados, são transformados em informações úteis ao processo decisório, não somente para análise e reconhecimento de problemas e pontos de melhoria, mas, principalmente, para a efetivação de ações que proporcionam a melhora ou a solução de tais situações levantadas.

\section{DIAGNÓSTICO DA SITUAÇÃO}

Partindo do pressuposto de que o processo decisório é composto por pessoas e ferramentas, e que as organizações atuam em um cenário de alto desenvolvimento tecnológico com uma realidade econômica em constante movimentação, torna-se importante analisar de que forma gestores e ERPs atuam, de modo a garantir a continuidade da organização (Gordon \& Narayanan, 1984). Todavia, é importante destacar que existe nas organizações uma preocupação quanto ao alinhamento de conceitos subjetivos com os 
objetivos da empresa, para que a autonomia de fato contribua com os resultados esperados pelo conjunto.

As organizações levam em consideração informações e características pessoais de seus gestores ao tomarem decisões. As influências psicológicas presentes no processo decisório estão representadas pelo uso de heurísticas, decorrentes vieses cognitivos e por aspectos emocionais, culturais, éticos e espirituais. Já as influências lógicas são representadas pela racionalidade, pelos paradigmas propostos e pelo contexto em que se observam (Pennings, Garcia \& Hendrix, 2005). Dessa forma, o processo decisório sofre influências de variáveis objetivas e subjetivas relacionadas aos dados econômicos e financeiros gerados pelos sistemas integrados de gestão, seguidas da percepção do gestor em relação a esses dados.

Este estudo parte da necessidade de compreender a maneira como sistemas do tipo ERP da Totvs são utilizados dentro da organização e como os aspectos subjetivos sejam considerados dentro dos sistemas, especialmente no controle do uso de heurísticas. Teve-se como questão orientadora a seguinte: Os ERP’s desenvolvidos pela Totvs utilizados pelas organizações para tomada de decisões financeiras, operacionais e estratégicas conseguem diminuir os vieses de decisão decorrentes do uso de heurísticas?

O estudo foi desenvolvido a partir da utilização de sistemas da empresa Totvs S. A., que, desde 2008, fortalece sua participação no mercado de softwares. A missão da Totvs é tornar-se a empresa provedora de informações gerenciais de qualidade para empresas que atuam em diversos setores da economia.

Embora o escopo seja limitado às empresas que utilizam sistemas integrados de um único fornecedor, as empresas usuárias dos sistemas têm ramos de atividade e porte econômico variados, o que possibilita uma análise do modo como essas empresas exploram o sistema.

Por meio desta pesquisa, visa-se a contribuir para o desenvolvimento do sistema integrado ofertado no mercado pela empresa Totvs S. A., bem como contemplar aspectos cognitivos, de modo a oferecer aos gestores de empresas clientes informações úteis e válidas ao processo decisório. A apresentação dessas informações, respeitando-se a maneira como os gestores analisam e interpretam seus dados, contribui para decisões 
mais assertivas e ágeis, proporcionando aos clientes maior competitividade e agilidade no processo gerencial e decisório.

\section{REVISÃO DA LITERATURA}

Com a finalidade de alcançar os objetivos propostos pela pesquisa na tentativa de compreender como os indivíduos utilizam sistemas ERPs para a tomada de decisão por meio de uma abordagem cognitiva, apresentam-se conceitos relacionados aos sistemas de informação do tipo ERP e ao processo cognitivo de decisão, especialmente no tocante a heurísticas.

\section{Sistemas de informação}

Para atender a diversos graus de complexidade organizacional, os sistemas de informação foram desenvolvidos com estruturas específicas, para que os dados armazenados fossem disponibilizados em formato de informação conforme as necessidades dos usuários representantes dos níveis organizacionais. Sistemas compreendidos como processadores estão na base da organização e tendem a ser suficientemente estruturados, de modo a executar tarefas e tomar decisões anteriormente planejadas. Logo, as atividades operacionais programadas para serem executadas com o acompanhamento desses sistemas têm alto nível de assertividade, uma vez que são plenamente moldadas. Sistemas de controle e execução operacional do negócio são sistemas que proporcionam controle e gerenciamento da atividade organizacional, são estruturados e obedecem a parâmetros. São realizados de acordo com as regras de negócio definidas pela organização no momento da implantação, garantindo uma operação estruturada e a qualidade das informações geradas para apoio ao gerenciamento e controle operacional do negócio. Já os sistemas controladores apresentam uma visão de indicadores e, por isso, tendem a atender a diversas áreas do processo organizacional, com a finalidade de gerir o negócio com qualidade, garantindo o bom desempenho da organização à medida que apresentam indicadores de desempenho que refletem o andamento das operações. Os sistemas táticos ocupam o 
topo da pirâmide e estão voltados a atender à alta gestão, fornecendo informações combinadas a outras diversas áreas de negócio, proporcionando uma informação da organização de modo a permitir ao gestor tomar decisões assertivas e estratégicas. Tendem a ser menos estruturados, mas suficientemente flexíveis, a fim de garantir que uma mesma informação seja analisada por perspectivas diversas. Logo, a classificação dos sistemas de informação contempla informações estruturadas, definidas e codificadas por meio de uma estrutura preestabelecida, e também por meio de informações não estruturadas consideradas não contextualizadas, podendo ser computadorizadas ou não (Falsarella, Beraquet \& Jannuzzi, 2003).

Os ERPs são bons exemplos de sistema de controle e execução do negócio; têm a propriedade de colaborar para o desenvolvimento das atividades organizacionais de forma integrada e também de controlar essa execução, pois integram diversas áreas da empresa e têm a capacidade de organizar e armazenar registros para que sejam utilizados no processo de gestão. A proposta da implantação dos ERPs, sobretudo nas grandes organizações, é para proporcionar à gestão maior visão sobre a operação. Funcionalidades como conformidade regulamentar, reengenharia de processos, integração de operações e suporte às decisões solidificaram a aderência na utilização de sistemas ERPs nas organizações (Robey, Ross \& Boudreau, 2002). Os ERPs são modulares, isto é, podem ser adquiridos por módulos para o atendimento de determinada área de operação da empresa. Ainda assim, a aquisição ou implantação pode ser feita por pacotes, por diversos módulos em um único sistema para atender a diversas áreas da organização de forma integrada. $\mathrm{Na}$ perspectiva da empresa, a implantação de ERPs é um processo demorado e demanda altos investimentos relacionados à tecnologia da informação, o que exige um escopo operacional amplo e complexo, de modo a atender a todas as particularidades da organização (Fan, Chang, Hsieh \& Wang, 2008).

A utilização de ERPs, porém, não garante controle operacional e melhora no desempenho das organizações. Para compreender melhor essa percepção, foram desenvolvidos estudos com a finalidade de identificar quais fatores podem comprometer os resultados obtidos pela utilização de sistemas, sejam aqueles decorrentes do processo de implantação, sejam aqueles apresentados durante a utilização dos sistemas já na atividade organizacional. 
Para que os ERPs ofereçam a padronização e o compartilhamento de informações, é necessário oferecer opções de parâmetros em que é possível transferir parte da inteligência dos gestores ao sistema, de modo que decisões sejam estruturadas. Todavia, ao tratar do processo decisório, existem questões ainda não conhecidas pelos gestores, além de possíveis alterações no cenário de atuação das organizações, o que exige flexibilidade para a estruturação dos dados.

Portanto, para tomar decisões estratégicas e flexíveis, a inteligência do gestor atua de forma isolada, os ERPs não moldarão esse tipo de operação. Logo, medidas devem ser tomadas a partir de informações que não necessariamente se encontram no banco de armazenamento do sistema, mas no ambiente em que a organização atua e, principalmente, na experiência do gestor (Colangelo, 2009).

Existem várias perspectivas de evolução de estudos relacionadas à maneira como os ERPs são efetivamente empregados nas organizações. Mayere, Grabot e Bazet (2008) realizaram estudos sob uma abordagem socioconstrutivista a partir do processo de implementação e utilização de ERPs, considerando aspectos da reação humana em relação à ferramenta, destacando a necessidade de customização da ferramenta e a baixa aceitação ou aderência do produto à realidade organizacional (Mayere, Grabot \& Bazet, 2008).

Os ERPs são vistos como importantes ferramentas no processo de tomada de decisão, sendo de grande valia ao gestor munido de informações tempestivas e fidedignas. Entretanto, há pessoas que, mesmo utilizando as informações geradas, usam atalhos cognitivos (heurísticas) em suas decisões, o que ocasiona vieses. Este estudo tem como objetivo identificar quais são essas heurísticas e se elas podem ser previstas no delineamento dos sistemas.

\section{Tomada de decisão}

O processo decisório racional é complexo, composto por fases: definição do problema, identificação dos critérios a serem considerados na decisão, a ponderação de critérios, a geração de alternativas para a solução do problema, classificação das alternativas para a solução do problema em relação aos critérios adotados para tal solução, identificação de solução ótima para o problema. Todavia, embora os passos façam parte da teoria da 
utilidade esperada, explicando a racionalidade, nem sempre essa decisão ocorre. Simon, em 1955, já contrariava essa teoria, discutindo que a racionalidade é limitada.

De acordo com estudos de Simon (1955), ao tomar decisões, as pessoas buscam satisfação, solução de um problema ou melhora de uma situação, e não otimização. Assim, à medida que as decisões atendem à necessidade de um conjunto de ideias e ideais, tornam-se mais assertivas, pois é necessário que haja o equilíbrio entre as necessidades e os interesses (Anthony \& Govindarajan, 2002). Em seu texto seminal, Simon (1955) discute que não é possível que o agente tomador de decisão tenha conhecimento dos custos das alternativas, dos pesos e dos componentes necessários para compará-las. Isso porque existe uma limitação de capacidade não só de conhecimento, mas de processamento das variáveis envolvidas nos modelos racionais de decisão.

Ampliando a discussão sobre a racionalidade limitada, Kahneman e Tversky (1979) apontam que as decisões mudam sob diferentes condições de risco - teoria do prospecto. Por eles desenvolvida, essa teoria postula que a função de valor para o ganho é diferente da função de valor para a perda, da mesma forma que dão um peso diferente aos resultados com algum grau de incerteza. Ou seja, as pessoas dão peso inferior aos resultados prováveis quando comparados aos resultados obtidos com certeza. Essa tendência, conhecida como "efeito certeza", representa o sentimento de aversão à perda contido nos tomadores de decisão, em que o julgamento do indivíduo exposto à incerteza desvia-se substancialmente da racionalidade (Macedo, 2003). Outra característica estudada pela teoria do prospecto é o efeito de isolamento, ou seja, quando uma mesma escolha é apresentada de maneira diferente, as pessoas descartam componentes que são compartilhados por diversas alternativas a serem selecionadas.

Para Kahneman e Tversky (1979), a decisão acontece em duas fases distintas: na primeira ocorre a edição, ou seja, as opções são organizadas e reformuladas de modo que tornem mais simples o processo de seleção; na segunda fase, há a avaliação dos resultados possíveis - nessa, o tomador de decisão escolhe o resultado de maior valor expresso em escalas que apresentam o impacto da probabilidade do resultado possível, e a outra escala mostra o valor subjetivo das alternativas propostas para a decisão (Cesar, Perez, Vidal \& Coda, 2012). Esses estudos sinalizam uma possibilidade para o delineamento de sistemas de apoio à decisão, especialmente no tocante ao arranjo das alternativas para decisão. 


\section{Heurísticas e vieses de decisão}

Embora os limites da racionalidade sejam conhecidos e modelos descritivos considerem a possibilidade do sacrifício de uma melhor alternativa em detrimento de outra razoável, não são elencadas as características para a definição de como esse julgamento é feito, não havendo um diagnóstico sobre como os vieses sistemáticos podem afetar a tomada de decisão. Modelos descritivos consideram que pessoas empregam atalhos ou estratégias simplificadoras para guiar as decisões a serem tomadas. A essas estratégias damos o nome de "heurísticas", que servem como mecanismos para interpretar o ambiente em que as decisões são requeridas. O uso de heurísticas muitas vezes viola as leis da lógica, da probabilidade ou outros mecanismos de escolha por alternativas no processo de tomada de decisão. Dessa forma, pode-se notar que as heurísticas têm aspectos positivos e negativos em relação à acurácia da decisão decorrente do uso dessas.

Gigerenzer, Todd e The ABC Research Group (1999) definem as heurísticas como métodos, sequências de operação para busca de decisões em um espaço de problemas; definem uma parte estratégica e ignoram as demais informações, tornando a análise das decisões rápidas, uma vez que se baseiam na utilização de um baixo volume de tempo, conhecimento e computação para efetivação de uma escolha.

Sobre a utilização de heurísticas de forma natural pelos indivíduos, pela sociedade e até mesmo como evolução do conhecimento, Boyd e Richerson (2005) criaram uma estrutura de características que requer a utilização de atalhos no processo decisório. A partir das ramificações que envolvem o processo decisório, é possível mapear os atalhos que envolvem esse processo indo ao encontro de Maidique (2011) sobre a utilização de heurísticas não ser necessariamente uma ação não racional, mas caracterizada pela utilização consciente de atalhos.

Em ambientes de incertezas, a utilização de heurísticas como ferramenta que ultrapassa os limites da racionalidade são importantes para a tomada de decisão gerencial. A árvore de decisões colabora para a condução dos gestores, a geração e consequente seleção de alternativas necessárias ao processo decisório. Resultados binários conduzem o tomador de decisões a resultados obtidos por meio de uma combinação de informações obtidas por dados e expertises, promovendo uma acurácia considerável. 
A utilização de heurísticas e vieses abarcam características de utilidade e aplicabilidade que pautam sua utilização no processo decisório. São elas:

- Modelos computacionais de heurísticas: O uso de modelos computacionais pode resultar em predições precisas. As heurísticas e os vieses focam campos verbais sem prover detalhes específicos sobre o desenho cognitivo do processo.

- Racionalidade ecológica: A racionalidade ecológica busca respostas relacionadas à possível existência de ambientes em que o uso de heurísticas para a tomada de decisão seja mais eficiente que outras estratégias. Em ambientes de incertezas, as heurísticas e os vieses podem representar o senso normativo, levando a um desempenho superior ao esperado por uma estratégia complexa.

- Menos pode ser mais: Em ambientes de incertezas, menos pode ser mais. As heurísticas não distinguem riscos de incertezas, logo, são assumidos os princípios de que decisões baseadas em heurísticas nunca terão a mesma acurácia que escolhas racionais, porém, tais análises exigem bem mais esforços.

Heurísticas são mecanismos de atalho que, mesmo de forma inconsciente, colaboram para que os indivíduos tomem decisões rápidas. Por meio das heurísticas, os julgamentos e as percepções são breves por serem baseados em experiências anteriores, ou ainda em suposições do agente (Bzerman, 2004), mas trazem o risco de os atalhos poderem desconsiderar fatores importantes no processo decisório.

As heurísticas podem ser categorizadas em três tipos: disponibilidade, representatividade e ancoragem/ajuste. A heurística de disponibilidade leva o ator da decisão a analisar com mais proximidade as informações que estão mais próximas ou disponibilizadas de forma recente, dando a ele a visão de que esses dados são mais relevantes ou têm maior peso. A heurística da representatividade define que indivíduos tendem a tomar decisões baseadas em um grupo (ou categoria) de informações ou características ao qual a situação analisada se assemelha. A heurística da ancoragem/ajuste prevê que pessoas partam de um valor inicial, ajustando-o até a definição da decisão final; a âncora, ou valor inicial, é estabelecida a partir de dados históricos, de acordo com características de apresentação 
dos problemas ou por meio da junção de informações aleatórias. Dessa forma, valores ancorados de maneiras distintas podem produzir resultados diferentes para a solução de um mesmo problema.

Como atalhos cognitivos, as heurísticas levam a vieses de decisão, erros previsíveis que podem causar um desvio à lógica e à racionalidade. O Quadro 1 apresenta os vieses relacionados aos diferentes tipos de heurísticas.

QUADRO 1 - Vieses relacionados às heurísticas

\begin{tabular}{|c|c|}
\hline Vieses & Descrição \\
\hline \multicolumn{2}{|c|}{ Vieses que emanam da heurística da disponibilidade } \\
\hline $\begin{array}{l}\text { Facilidade de } \\
\text { lembranças }\end{array}$ & $\begin{array}{l}\text { Indivíduos julgam que eventos mais facilmente recuperados da memória com } \\
\text { base na recentidade e vivides são mais numerosos do que eventos de igual } \\
\text { frequência cujos exemplos são lembrados com menos facilidade. }\end{array}$ \\
\hline Recuperabilidade & $\begin{array}{l}\text { A avaliação que os indivíduos fazem da frequência de eventos sofre viés com } \\
\text { base no modo como as estruturas e suas memórias afetam o processo de busca. }\end{array}$ \\
\hline $\begin{array}{l}\text { Associações } \\
\text { pressupostas }\end{array}$ & $\begin{array}{l}\text { Indivíduos tendem a superestimar a probabilidade de dois eventos ocorrerem } \\
\text { concomitantemente com base no número de associações semelhantes que } \\
\text { podem recordar facilmente, seja pela experiência, seja por influência social. }\end{array}$ \\
\hline \multicolumn{2}{|c|}{ Vieses que emanam da heurística da representatividade } \\
\hline $\begin{array}{l}\text { Insensibilidade aos } \\
\text { índices básicos }\end{array}$ & $\begin{array}{l}\text { Ao avaliar a probabilidade de eventos os indivíduos tendem a ignorar os } \\
\text { índices básicos caso seja fornecida qualquer outra descrição informativa - } \\
\text { mesmo que seja irrelevante. }\end{array}$ \\
\hline $\begin{array}{l}\text { Insensibilidade ao } \\
\text { tamanho da amostra }\end{array}$ & $\begin{array}{l}\text { Ao avaliar a confiabilidade de informações amostrais, indivíduos } \\
\text { frequentemente falham na avaliação do papel do tamanho da amostra. }\end{array}$ \\
\hline $\begin{array}{l}\text { Interpretações erradas } \\
\text { da chance }\end{array}$ & $\begin{array}{l}\text { Indivíduos esperam que uma sequência de dados gerada por um processo } \\
\text { aleatório aparecerá “aleatória” mesmo quando a sequência for muito curta } \\
\text { para que essas expectativas sejam estatisticamente válidas. }\end{array}$ \\
\hline Regressão à média & $\begin{array}{l}\text { Indivíduos são propensos a ignorar o fato de que eventos externos tendem a } \\
\text { regredir à média em tentativas subsequentes. }\end{array}$ \\
\hline A falácia da conjunção & $\begin{array}{l}\text { Indivíduos julgam erroneamente que conjunções (dois eventos ocorrendo } \\
\text { concomitantemente) são mais prováveis do que um conjunto mais global de } \\
\text { ocorrências do qual a conjunção é um subconjunto. }\end{array}$ \\
\hline
\end{tabular}


QUADRO 1 - Vieses relacionados às heurísticas

\begin{tabular}{|c|c|}
\hline Vieses & Descrição \\
\hline \multicolumn{2}{|c|}{ Vieses que emanam da ancoragem e do ajuste } \\
\hline $\begin{array}{l}\text { Ajuste insuficiente da } \\
\text { âncora }\end{array}$ & $\begin{array}{l}\text { Indivíduos estimam valores com base em um valor inicial (derivado de } \\
\text { eventos passados, atribuição aleatória ou qualquer informação disponível) } \\
\text { e usualmente fazem ajustes insuficientes a partir daquela âncora para } \\
\text { estabelecer um valor final. }\end{array}$ \\
\hline $\begin{array}{l}\text { Vieses de eventos } \\
\text { conjuntivos e } \\
\text { disjuntivos }\end{array}$ & $\begin{array}{l}\text { Indivíduos exibem um viés em relação à superestimação da probabilidade de } \\
\text { eventos conjuntivos e à subestimação da probabilidade de eventos disjuntivos. }\end{array}$ \\
\hline Excesso de confiança & $\begin{array}{l}\text { Indivíduos tendem a demonstrar excesso de confiança quanto à infabilidade } \\
\text { de seus julgamentos ao responder perguntas moderadas ou extremamente } \\
\text { difíceis. }\end{array}$ \\
\hline \multicolumn{2}{|l|}{ Dois vieses mais gerais } \\
\hline $\begin{array}{l}\text { A armadilha da } \\
\text { confirmação }\end{array}$ & $\begin{array}{l}\text { Indivíduos tendem a buscar informações confirmatórias para o que eles } \\
\text { acham que é verdade e deixam de procurar evidências desconfirmatórias. }\end{array}$ \\
\hline $\begin{array}{l}\text { Previsão retrospectiva } \\
\text { (hindsight) e a } \\
\text { maldição do } \\
\text { conhecimento }\end{array}$ & $\begin{array}{l}\text { Após saber se um evento ocorreu ou não, indivíduos tendem a superestimar } \\
\text { até que grau eles teriam previsto o resultado correto. Além do mais, não } \\
\text { ignoram informações que eles têm, mas que os outros não têm ao prever } \\
\text { o comportamento alheio. }\end{array}$ \\
\hline
\end{tabular}

Fonte: Bazerman (2004).

Uma pesquisa realizada por Gavetti (2005) sobre ferramentas gerenciais mostrou que heurísticas são adotadas de forma persistente nas organizações como parte do processo decisório, independentemente das mudanças de ambiente. $\mathrm{O}$ seu uso pode auxiliar o processo decisório em ambientes de incertezas com limitação de informações disponíveis para a utilização de ferramentas racionais, bem como com limitação de tempo para análise das informações, alternativas e consequências das escolhas disponíveis ao processo (Bazerman \& Moore, 2009). O uso de atalhos cognitivos, portanto, está presente no processo decisório como uma caixa de ferramentas padrão, e não de maneira isolada ou independente de outras análises. Isso sugere que se possa modelar algumas dessas heurísticas para incorporá-las aos sistemas de informação integrados. 


\section{MÉTODO}

A pesquisa foi realizada por meio de uma abordagem qualitativa com a finalidade de compreender a complexidade e a integração dos elementos pesquisados (Lüdke \& André, 1986). Para o estudo, foram selecionados gestores que utilizam o sistema ERP Totvs 12 da empresa Totvs S. A. Dentre os sistemas desenvolvidos pela empresa, o Totvs 12 foi o selecionado por estar voltado a atender indústrias e empresas de médio e grande porte, além de ser desenvolvido sob regras de negócio alinhadas com as normas brasileiras fiscais e contábeis. O sistema tem módulos de controladoria, finanças, logística, materiais e obrigações fiscais, além da integração com produtos de recursos humanos, gerenciamento de relacionamento com clientes e inteligência de negócios.

Os dados utilizados no estudo são primários e foram obtidos diretamente por meio de entrevistas semiestruturadas com cinco gestores, seguindo um roteiro preestabelecido (Kvale, 1996), realizadas dentro das empresas em que os gestores trabalham de forma organizada e sem interrupções. Todas as entrevistas foram gravadas e posteriormente, transcritas para análise. As entrevistas buscavam captar: a estruturação de sistemas integrados de gestão com a finalidade de compreender a forma como os sistemas são utilizados, seja para a operação, seja para a gestão; o uso de heurísticas no processo decisório a partir das informações geradas pelo sistema analisado. Além das questões qualitativas aplicadas nas entrevistas, ao final de cada uma delas foi solicitado ao entrevistado que respondesse um questionário contendo situações relacionadas às heurísticas e vieses propostos por Bazerman (2004), de modo a representar o nível de afetividade ou racionalidade aplicada pelos gestores entrevistados. Para cada situação, o entrevistado deveria responder, numa escala categórica, afirmando sua concordância total por meio do "sim" ou discordância total por meio do "não" à situação apresentada. Essas situações estão relacionadas a vieses cognitivos possíveis em seu dia a dia.

Todos os entrevistados fazem parte do processo decisório nas organizações em que atuam e ocupam os cargos de gerente de operações, gerente administrativo, diretor de informática, controller e diretor financeiro. Os ramos de atividade das empresas nas quais atuam variam entre bens de consumo, bens de capital, metal mecânico e plástico e serviços 
hospitalares, de modo a garantir a diversidade das necessidades de utilização do sistema integrado como ferramenta para tomada de decisão.

\section{PROPOSTA DE SOLUÇÃO}

Com o objetivo de compreender a origem das informações utilizadas no processo decisório nos relatórios gerenciais periódicos, buscou-se compreender a capacidade de os ERPs emitirem relatórios válidos ao processo de gestão das operações organizacionais. Observou-se que os sistemas oferecem, por meio de seus relatórios, uma base sintetizada do dia a dia da organização e a maior parte dos relatórios utilizados no processo de gestão das operações é extraída dos ERPs, mas muitos relatórios necessitam de ajustes para atender às necessidades de visualização ou agrupamento de informações, uma vez que os relatórios disponibilizados pelo produto de forma padronizada proporcionam menor tempo de processamento e/ou análise dos dados, tornando o ajuste necessário para a otimização da interpretação desses. Há percepção de que a interpretação de dados também pode ser feita de forma personalizada e não estruturada, o que exige uma pessoa capacitada a interpretar os dados apresentados; caso não haja, esses serão apenas dados armazenados, e não informados. Também se discutiu que para informações específicas de determinadas áreas, os ERPs não fornecem informações, pois tais operações não utilizam o sistema, mas, sim, sistemas periféricos que, devido às particularidades do ramo de operação da empresa, não são contidos no sistema integrado.

Visando a conhecer se o sistema implantado tem as mesmas estruturas definidas pelo seu fornecedor, após a implantação do sistema ERP, verificou-se se foi necessária alguma customização no produto padrão adquirido. Observou-se que há customizações que facilitam o processo operacional, de modo a não somente atender às necessidades específicas da organização, mas também a facilitar o manuseio do sistema, minimizando a margem de erros decorrentes da utilização indevida da ferramenta, uma vez que os padrões sugeridos pela fábrica de software não atendem a todos os ramos de atividade com a mesma assertividade e atenção aos detalhes operacionais e à usabilidade do produto.

Ao investirem em sistemas integrados de gestão, as empresas buscam eliminar a utilização de diversos sistemas, sistemas independentes por área operacional com a ex- 
pectativa de utilizar somente os ERPs, que são considerados, portanto, a espinha dorsal das operações empresariais (Perez \& Ramos, 2013). Os dados mostraram que, dentre os cinco respondentes, dois utilizam outros sistemas além dos ERPs para sua operação. Uma das empresas, atuante no ramo de bens de consumo, possui um sistema periférico relacionado ao gerenciamento de estoques; a outra, atuante do ramo de serviços hospitalares relacionados à epidemiologia, usa o sistema para acompanhamento das necessidades dos pacientes. Um terceiro entrevistado aponta que os ERPs não são eficientes para a otimização da administração logística de sua organização.

Quanto ao uso de heurísticas, os entrevistados afirmaram utilizar ferramentas tradicionais para pautar suas decisões, como fluxo de caixa, análise de investimentos utilizando indicadores como break even point e taxa interna de retorno. Segundo eles, por se tratarem de decisões relacionadas às tendências econômicas, as frequências das informações não tendem a influenciá-los, já que a sazonalidade da operação está sendo considerada. Além disso, conta-se com os dados extraídos do ERP para conhecimento dos dados históricos. Já a projeção dos números é feita com base em diversos indicadores de mercado, tais como índice de inflação e indicadores de desempenho financeiros próprios da organização. Quanto à influência das emoções na tomada de decisão, os entrevistados destacam o contraponto da decisão, afirmando que, ao tomarem decisões financeiras, existe uma relação entre racionalidade e afeto, especialmente quanto à sensação do que é importante fazer; no entanto, são os dados financeiros e econômicos que definem a ação a ser tomada. Quanto à heurística de representatividade, os entrevistados apontam que a tendência de os indivíduos utilizarem os mesmos dados do passado para pautar suas decisões não ocorre porque as informações capturadas tendem a se modificar. A tendência econômica do cenário em questão é relevante. Assim, as organizações buscam interpretar e compreender dados que refletem o cenário atual. Mas, em contraste, afirmam que há uma curva de aprendizagem, sugerindo o uso de expertise para decisões, o que é, claramente, o uso de heurística. Observou-se também a utilização de vieses relacionados à ancoragem de cenário desejado e, portanto, ajustes baseados na experiência do gestor são vistos como garantidores da eficácia do ajuste a ser realizado. Os entrevistados apontam que há limites para a racionalidade conforme estudado por Simon (1955). 
A influência de sentimentos e expectativas dos gestores em decisões relacionadas às questões operacionais estão presentes também no que se refere à frequência dos fatores que levaram ao ponto de melhoria ou ao debate do problema, que passaram a ser encarados como de maior relevância.

Outro aspecto importante destacado pelos entrevistados foi a influência das emoções ao se tomar decisões estratégicas. As emoções, na visão deles, podem indicar a necessidade iminente de se alterar a maneira como se opera, já que essa é uma rotina altamente influenciada pela sensibilidade das pessoas envolvidas no processo.

\section{CONSIDERAÇÕES FINAIS}

Os dados apontam que nas decisões relacionadas às finanças a influência de vieses apresentou-se menos importante. Os entrevistados destacaram que decisões dessa natureza são pautadas em informações e indicadores objetivos, o que minimiza a influência de fatores cognitivos eventualmente presentes na visão dos gestores. Logo, os sistemas são ferramentas importantes para decisões dessa natureza, já que têm a capacidade de centralizar e mensurar informações importantes para a sustentação da decisão a ser tomada.

Nas decisões relacionadas à operação das organizações, os sistemas apresentaram-se menos utilizados quando comparados com a influência de aspectos cognitivos. Um ponto considerado por todos os entrevistados foi a presença de fatores não financeiros, bem como a influência de emoções ao analisarem dados necessários para a tomada de decisões operacionais. Decisões dessa natureza tendem a ser estratégicas, não visando apenas a fatores objetivos. Estão relacionadas à experiência do gestor, que relaciona os dados apresentados pelo sistema a fatos vivenciados pela organização, considerando as informações necessárias para pautar as decisões. Quanto às decisões relacionadas ao planejamento estratégico, essas contêm pouca influência dos sistemas integrados de gestão.

Os resultados do estudo evidenciam que sistemas integrados de gestão do tipo ERP colaboram para decisões estruturadas, mas não se aplicam adequadamente a decisões mais subjetivas, que pouco contam com o apoio dessas informações. Isso sinaliza que há um desafio de propor sistemas que sejam capazes de utilizar heurísticas semelhantes às adotadas por humanos, especialmente para decisões em ambientes instáveis ou incertos. 


\section{REFERÊNCIAS}

Amaral, S. A., \& Sousa, A. J. F. P. (2011). Qualidade da informação e intuição na toada de decisão organizacional. Perspectivas em Ciência da Informação, 16(1), 133-146.

Anthony, R. N., \& Govindarajan, V. (2002). Sistemas de controle gerencial. São Paulo: Atlas.

Bazerman, M. H. (2004). Processo decisório (5a. ed.). Rio de Janeiro: Elsevier.

Bazerman, M. H., \& Moore, D. A. (2009). Judgment in managerial decision making (7th ed.). New Jersey: John Wiley \& Sons.

Boyd, R., \& Richerson, P. J. (2005). Solving the puzzle of human cooperation. In S. Levinson (Ed.), Evoluation and Culture. Cambridge, MA: MIT Press.

Cesar, A. M. R. V. C., Perez, G., Vidal, P. G., \& Coda, R. (2012). Neuroaccounting: Um modelo para análise de processo de tomada de decisão. Revista de Contabilidade Vista \& Revista, 23(2), 131-162.

Colangelo, L., Filho (2009). Implantação de sistemas ERP: Um enfoque a longo prazo. São Paulo: Atlas.

Falsarella, O. M., Beraquet, V. S. M., \& Jannuzzi, C. A. S. C. (2003). Informação empresarial: Dos sistemas transacionais à latência zero. Transformação, número especial, 141-156.

Fan, R.-E., Chang, K.-W., Hsieh, C.-J., Wang, X.-R., \& Lin, C.-J. (2008). LIBLINEAR: A library for large linear classification. Journal of Machine Learning Research, (9), 1871-1874.

Gavetti, G. (2005). Cognition and hierarchy: Rethinking the microfoundations of capabilities' development. Organization Science, 16(6), 599-617, 2005.

Gigerenzer, G., Todd, P. M., \& The ABC Research Group. (1999). Simple heuristics that make us smart. New York: Oxford University Press.

Gordon, L. A., \& Narayanan, V. K. (1984). Management accounting systems, perceived environmental uncertainty and organizational structure: An empirical investigation. Accounting, Organizations and Society, 9(1), 33-47.

Kahneman, D., Knetsch, J., \& Thaler, R. (1991). Anomalies: The endowment effect, loss aversion, and status quo bias. Journal of Economic Perspectives, 5(1), 193-206.

Kahneman, D., \& Tversky, A. (1979). Prospect theory: An analysis of decisions under risk. Econometrica, 47(2), 263-291. 
Kvale, S. (1996). InterViews. London: Sage Publications.

Lüdke, M., \& André, M. E. D. A. (1986). Pesquisa em educação: Abordagens qualitativas. São Paulo: EPU.

Macedo, J. S., Jr. (2003). Teoria do prospecto: Uma investigação utilizando simulação de investimentos (Tese de doutorado, Universidade Federal de Santa Catarina, Florianópolis, Brasil).

Maidique, M. A. (2011). Decoding intuition for more effective decision-making. Harvard Business Review. Recuperado de https://hbr.org/2011/08/decoding-intuition-for-more-ef.

Mayere, A., Grabot, B., \& Bazet, I. (2008). The mutual influence of the tool and the organization. In A. Mayere, B. Grabot, \& I. Bazet (Eds.), ERP Systems and organisational change: A socio-technical insight. London: Springer.

Pennings, J. M., Garcia, P., \& Hendrix, E. (2005). Towards a theory of revealed economic behavior: The economic-neurosciences interface. Journal of Bioeconomics, 7(2), 113-127.

Perez, G., \& Ramos, I. (2013). Understanding organizational memory from the integrated management systems (ERP). Proceedings of the International Conference on Information Systems and Technology Management 10, São Paulo. Recuperado de http://www.contecsi. fea.usp.br/envio/index.php/contecsi/10contecsi/paper/viewFile/346/84.

Robey, D., Ross, J. W., \& Boudreau, M. (2002). Learning to implement enterprise systems: An exploratory study of the dialectics of change. Journal of Management Information Systems, 19(1), 17-46.

Simon, H. A. (1955). Behavioral model of rational choice. The Quarterly Journal of Economics, 69(1), 99-118. 